SCIREA Journal of Materials http://www.scirea.org/journal/Materials

March 7, 2022

Volume 7, Issue 1, February 2022

https://doi.org/10.54647/materials43168

\title{
Microstructure and properties of porous ceramics synthesized using Kubuqi desert sand
}

\author{
Ru Fan ${ }^{1}$, Wenbin Wang ${ }^{1 *}$, Shaohua Wang ${ }^{1}, Z$ Li $^{1}$, Shuojiang Han ${ }^{1}$, Zhiming Shi ${ }^{1}$ \\ ${ }^{1}$ School of Materials Science and Engineering, Inner Mongolia University of Technology, \\ Hohhot 010051, China \\ *Corresponding author: Tel.: +8604716575752, Fax: +8604716575752 \\ E-mail: wangwenbinbeyond@163.com (Wenbin Wang*), 423708211@qq.com (Ru Fan), \\ 1815320180@qq.com (Shaohua Wang),3550521401@qq.com (Zhi Li),986609263@qq.com \\ (Shuojiang Han), shizm@imut.edu.cn (Zhiming Shi).
}

\begin{abstract}
Desert sand has the characteristics of large reserves, high quartz content, small and uniform particle size, low organic content and so on. High performance porous ceramic materials were prepared by particle stacking from Kubuqi desert sand, and the effects of forming pressure, holding time and sintering temperature on phase transformation, microstructure, sintering properties, mechanical properties and thermal conductivity of ceramics were investigated. The results show that the high temperature melting of feldspar phase in desert sand binds the quartz particles together to form a stable porous structure ranging from several microns to hundreds of microns, and the decomposition of ferric oxide leads to the formation of closed
\end{abstract}


pores. The obtained porous ceramics have excellent sintering properties, which is conducive to high value-added desert applications.

Keywords: Desert sand; Porous ceramics; Sintering; Particle stacking; Phase transformation; Properties

\section{Introduction}

Porous ceramic is a kind of ceramic material with specific pore structure and porosity prepared by batching, molding and sintering processes [1], which has high temperature resistance, acid and alkali corrosion resistance, good biological inertia, good thermal shock resistance, adjustable pore structure and porosity, and good reuse performance. Porous ceramic is commonly used in refractory heat insulation materials, lightweight structural materials, sound-absorbing materials, filtration materials, catalyst carriers and ceramic sensors, which plays a critical role in industry, life, electronics, national defense and aerospace fields [2-9]. At present, the ordinary materials for the synthesis of porous ceramics are mainly high purity chemical materials and natural mineral materials. With the development of industry, mineral consumption is enormous, causing irreversible damage to the environment. In order to save resources and protect the environment, industrial solid wastes such as slag, red mud, fly ash and coal gangue are used to synthesize porous ceramics. However, solid wastes such as fly ash contain a certain proportion of heavy metal harmful substances, and the concentration of some elements $(\mathrm{Cd}, \mathrm{Cr}, \mathrm{Hg}, \mathrm{Se})$ exceeds the specified limit, which will produce potentially threatening toxic effects when used in the synthesis of porous ceramics $[10,11]$. In addition, distribution and reserves of industrial solid waste can not well meet the huge raw material consumption of ceramic industrial production, so it is of great significance to find a sustainable development type of raw material suitable for the ceramic industry.

China has vast desert coverage, accounting for about $13 \%$ of the country's total land area. 
Desert sand particles are irregular in shape and mainly composed of quartz and feldspar phases [12]. When the sand particles are heated to the melting temperature of feldspar, the feldspar phase will turn into a liquid phase, and the quartz particles of sands will be joined together. When the liquid volume and sand particle size distribution are controlled to an appropriate proportion, the contact area of desert sand particles will form a firm connection under the action of the liquid phase, and the non-contact area between particles will form natural pores. Finally, porous ceramics with good porosity can be obtained without adding additives. Compared with other material or process (adding pore-forming agent process [13], organic foam impregnation process [14], sol-gel process [15], freeze-drying process [16]), the pore size of porous ceramics synthesized from desert sand (from several microns to hundreds of microns) is much larger than these methods (smaller than tens of microns), which has advantages such as abundant raw materials, simple process route, adjustable porosity and good mechanical properties and can greatly reduce the synthesis cost and is suitable for low-cost and sustainable production of porous ceramics.

In this paper, natural desert sand was used as raw material to synthesize porous ceramics, and the effects of forming pressure, sintering temperature and holding time on phase transformation, porosity morphology and various properties of porous ceramics were investigated, aiming to provide new technical support for environmental protection synthesis of porous ceramics.

\section{Experimental procedure}

\subsection{Materials and Methods}

The porous ceramic materials were synthesized by particle stacking with Kubuqi desert sand as raw material, and the chemical composition and average particle size are given in Table $\mathbf{1}$.

Table 1. The chemical composition $/ \mathrm{wt} \%$ and average particle size / $\mu \mathrm{m}$ of desert sand.

\begin{tabular}{llllllllll}
\hline Desert & $\mathrm{SiO}_{2}$ & $\mathrm{Al}_{2} \mathrm{O}_{3}$ & $\mathrm{Fe}_{2} \mathrm{O}_{3}$ & $\mathrm{CaO}$ & $\mathrm{K}_{2} \mathrm{O}$ & $\mathrm{MgO}$ & $\mathrm{Na}_{2} \mathrm{O}$ & $\mathrm{TiO}_{2}$ & Others \\
\hline
\end{tabular}




$\begin{array}{lllllllllll}\text { Kubuqi } & 79.62 & 8.42 & 2.38 & 2.19 & 2.01 & 0.76 & 1.90 & 0.30 & 2.37 & 176.3\end{array}$

\subsection{Sample preparation}

Firstly, the desert sand was screened by a vibrating screen, and separated into sand with different particle sizes (>20 mesh, 20-40 mesh, 40-60 mesh, 60-80 mesh, 80-100 mesh, 100-120 mesh, and 120-140 mesh). Secondly, sand with the highest proportion in a certain particle size range was selected as the precursor material for the synthesis of porous ceramics in order to consider the large-scale application. By comparing the proportion of sand particle size, 80-100 mesh of Kubuqi desert sand was selected as raw material. Then, the sand was evenly mixed with sodium silicate (adding ratio: $15 \mathrm{~g}$ sand: $1 \mathrm{~mL}$ sodium silicate (module 3.3 )) and put into cylindrical metal mold, which was pressed into green body with cylindrical shape by universal testing machine (SANS, SHT-4605, forming pressure of 10, 20, 30, 40, $50 \mathrm{MPa}$, holding time of $180 \mathrm{~s}$ ). Finally, the green body was sintered via a high temperature box resistance furnace (SIOM, SXL-1700) in different temperatures $\left(1100^{\circ} \mathrm{C}, 1150^{\circ} \mathrm{C}, 1200^{\circ} \mathrm{C}\right)$ for different holding time ( 2 h, 4 h, 6 h) under normal pressure, and cooled with the furnace.

\subsection{Test and analysis}

RIGAKU D/MAX-2500/PC X-ray diffractometer (Cu Ka radiation, 40 kV, $100 \mathrm{~mA})$ was used to analyze the ceramic phase, and MDI Jade was used for calculating the phase content. Linear shrinkage rate of ceramics was calculated according to the diameter changes of porous ceramics before and after sintering. Ceramics were cut by a low-speed diamond cutting machine, embedded in resin, polished and sprayed with gold, and then put into the scanning electron microscope (Benchtop SEM, JEOL, JCM-6000 NeoScope) to observe and analyze the ceramic microstructure. Morphology of ceramic was observed using a confocal laser scanning microscope (CLSM, ZEISS, AxioCam MRc 5). Based on Archimedes drainage method, the bulk density, apparent porosity and water absorption of ceramics were tested by referring to the boiling method of national standard GB/T 3810.3-2006 and an improved testing method [17]. The compressive strength of porous ceramics was tested according to 
national standard GB/T 1964-1996. There were 5 samples in each group, and the samples were cut directly from the samples. The sample specifications were cylinders with a diameter of $20 \pm 1 \mathrm{~mm}$ and a height of $20 \pm 1 \mathrm{~mm}$. The pressure direction of the sample was the same as the pressure direction of the sample during the test, and the pressure was applied uniformly at the speed of $20 \pm 5 \mathrm{~kg} / \mathrm{cm}^{2}$ per second. The bending strength of porous ceramics was tested according to national standard GB/T 1965-1996. The sample size is $120 \pm 2 \mathrm{~mm}$ in length, $20 \pm 1 \mathrm{~mm}$ in width and $10 \pm 1 \mathrm{~mm}$ in thickness, the span is $50 \pm 0.1 \mathrm{~mm}$, and the loading speed is $2 \pm 0.5 \mathrm{~N} / \mathrm{s}$. The thermal conductivity $(\mathrm{W} /(\mathrm{m} \cdot \mathrm{k}))$ of porous ceramics was measured by NETZSCH LFA467 laser thermal conductivity measuring instrument. The test temperature was $300^{\circ} \mathrm{C}$, the shielding gas was Ar, the sample diameter was $12.7 \mathrm{~mm}$, the thickness was $5.28 \mathrm{~mm}$. The permeability of porous ceramics was tested according to GB/T 1969-1996 (Sample diameter is $36 \mathrm{~mm}$, height is $10 \mathrm{~mm}$ ).

\section{Results and discussion}

\subsection{Phase composition of porous ceramics}

The X-ray diffraction patterns of porous ceramics synthesized from Kubuqi desert sand are shown in Fig. 1, and the calculation results of phase content are shown in Fig. 2. It can be seen that the quartz phase (JCPDS: 86-1630), feldspar phase (JCPDS: 89-6424) and a small part of glass phase appeared in the sintered sample. When the sintering temperature was $1100^{\circ} \mathrm{C}$ (Fig. 1a), there were more feldspar phases in the samples. In comparison, there are more feldspars in 80-100 mesh Kubuqi desert sand. The convexity degree of the diffraction peak indicates that the proportion of glass phase is small, which is consistent with the calculation results of glass phase in Fig. 2. Compared with other sintering temperatures, the glass phase content was the lowest at $1100^{\circ} \mathrm{C}$. When the forming pressure was different (Fig. 1b), the change of crystal phase content in each sample was not obvious, which means that the forming pressure has little influence on the crystal phase. By comparison, the forming pressure of $30 \mathrm{MPa}$ is conducive to the formation of more glass phases, so the following 
discussion is mainly focused on the samples under $30 \mathrm{MPa}$ forming pressure. In addition, Fig. 2 shows that the higher the temperature is, the greater the decomposition tendency of feldspar phase into glass phase is. The feldspar phase in desert sand is composed of potassium feldspar, albite and anorthite, and the feldspar phase will be transformed into quartz phase and glass phase at high temperature, suggesting that the higher the temperature is, the more liquid phase is formed in desert sand, as shown in equation (1). Finally, a large number of glass phases are formed, which act as junctions between desert sand particles to form a porous ceramic skeleton.

$$
\left(\mathrm{K}_{2} \mathrm{O}, \mathrm{Na}_{2} \mathrm{O}, \mathrm{CaO}\right) \cdot \mathrm{Al}_{2} \mathrm{O}_{3} \cdot 6 \mathrm{SiO}_{2} \rightarrow \mathrm{Liquid}+\mathrm{SiO}_{2}
$$
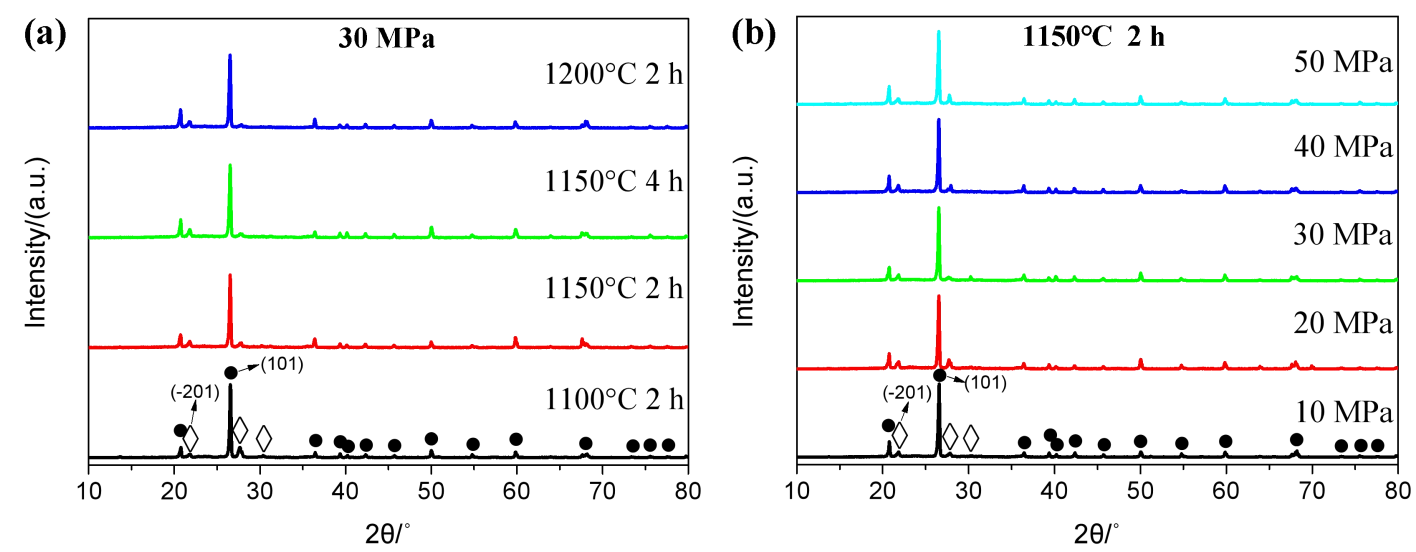

Fig. 1. XRD patterns of porous ceramics synthesized from Kubuqi desert sand ( $\bullet$ : Quartz phase and $\diamond$ : feldspar phase), (a) formed under $30 \mathrm{MPa}$, (b) sintered at $1150^{\circ} \mathrm{C}$ for $2 \mathrm{~h}$. 


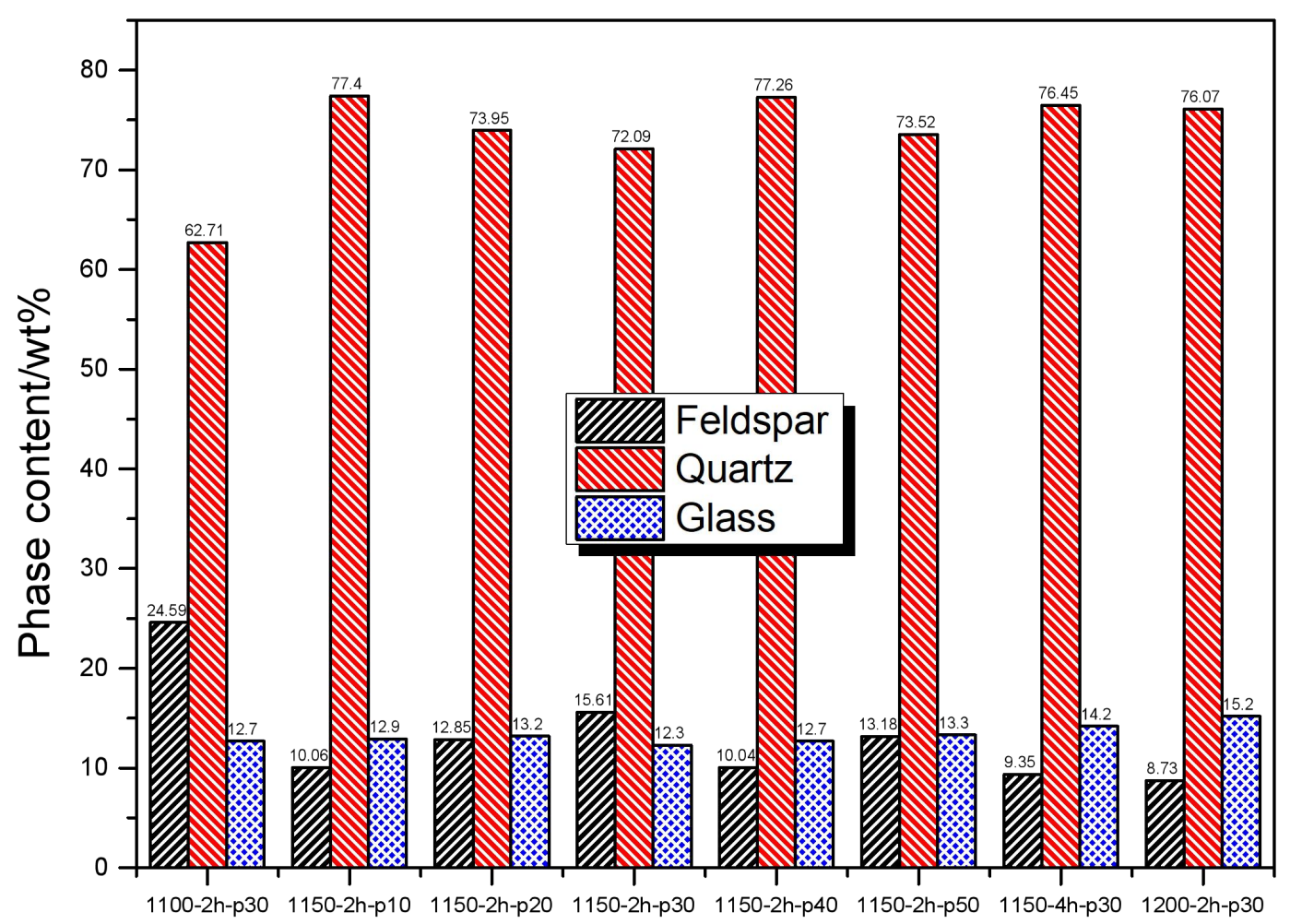

Sintering temperature, holding time and forming pressure

Fig. 2. Content of various phases in porous ceramics.

\subsection{Microstructure of porous ceramics}

Fig. 3 shows the SEM images of porous ceramics synthesized from Kubuqi desert sand. When forming pressure was $30 \mathrm{MPa}$ and the holding time was $2 \mathrm{~h}$, and the sintering temperature increased from $1100^{\circ} \mathrm{C}$ to $1150^{\circ} \mathrm{C}$, the connection area between porous ceramics particles increased slightly and the pore type was mainly open pore (Fig. 3a-Fig. 3b). When the holding time was extended from $2 \mathrm{~h}$ to $4 \mathrm{~h}$, a large number of connections were formed inside the porous ceramics and the number of closed pores increased (Fig. 3c). When the sintering temperature was $1200^{\circ} \mathrm{C}$, a large number of open pores in ceramics transformed into closed pores (Fig. 3d). The above results indicate that with the increase of temperature and holding time, the proportion of liquid phase formed by feldspar phase increases, which promotes the connection of particles, and the morphology of pores transforms from open pores $(30-300 \mu \mathrm{m})$ to closed ones $(5-100 \mu \mathrm{m})$. In addition, the iron trioxide in desert sand also breaks down into iron tetroxide and oxygen at high temperatures, releasing the gas to form a small number of 
spherical closed pores. At the same time, the observed change in ceramic color from red to black also confirms the transition from iron trioxide to iron tetroxide. In contrast, the increase of sintering temperature and holding time increases the contact area of sand particles, which plays a major role in the morphology change of porous ceramics.
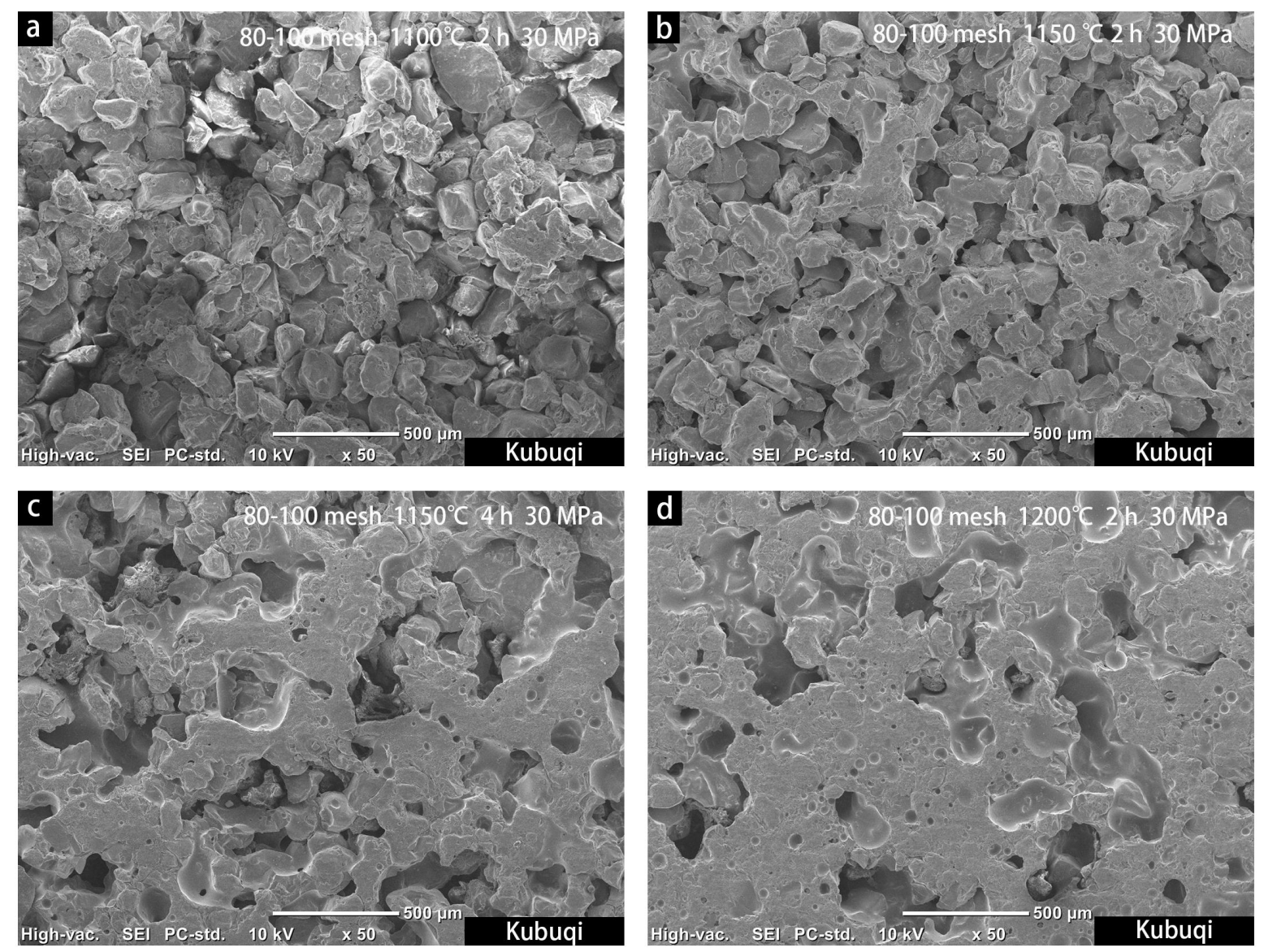

Fig. 3. SEM images of porous ceramics synthesized under $30 \mathrm{MPa}$ forming pressure, (a) $1100^{\circ} \mathrm{C} 2 \mathrm{~h}$,

(b) $1150^{\circ} \mathrm{C} 2 \mathrm{~h}$, (c) $1150^{\circ} \mathrm{C} 4 \mathrm{~h}$, (d) $1200^{\circ} \mathrm{C} 2 \mathrm{~h}$.

When forming under $10 \mathrm{MPa}$, sand particles in ceramic were relatively independent (Fig. 4a). When the pressure rose to $20 \mathrm{MPa}$, the sand particles began to melt, resulting in adhesion phenomenon (Fig. 4b). When the pressure was increased to 30-50 MPa, the adhesion area of sand particles became larger and the ceramics tended to densify (Fig. 3b, Fig. 4c-Fig. 4d), including open pores and a certain number of spherical closed pores. The pore size of porous ceramics was decreased with the increase of forming pressure, indicating that the forming pressure has a certain effect on reducing the pore size and the densification of ceramics. 

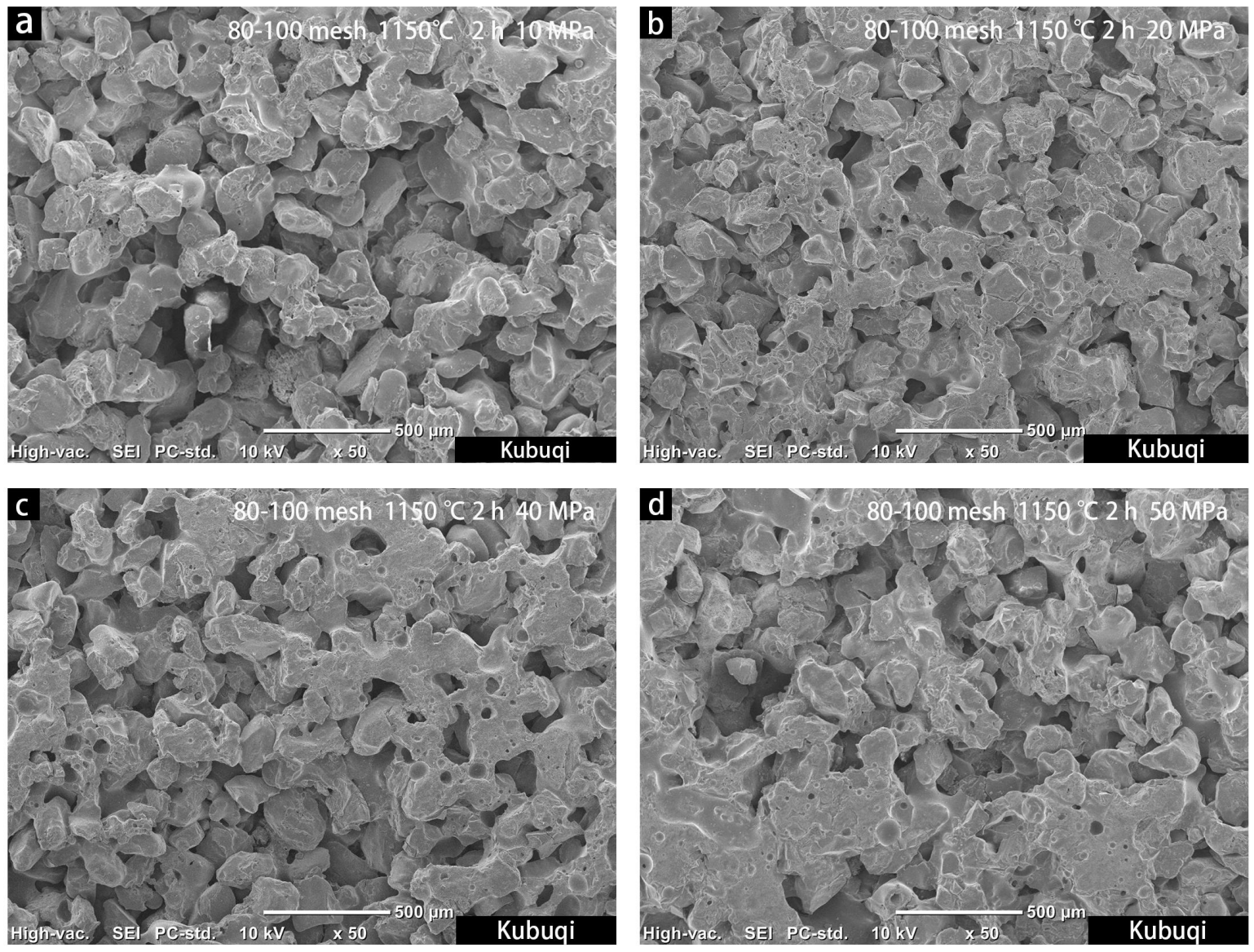

Fig. 4. SEM images of porous ceramics synthesized at $1150^{\circ} \mathrm{C}$ for $2 \mathrm{~h}$, (a) $10 \mathrm{MPa}$, (b) $20 \mathrm{MPa}$, (c) 40 MPa, (d) 50 MPa.

The images of confocal laser scanning microscope show the pore structure of porous ceramics, and the morphology of sand particles and precipitated glass phase (Fig. 5). When the sintering temperature was $1100^{\circ} \mathrm{C}$, the content of glass phase precipitated from the ceramics was low, and large area connection cannot be formed between desert sand particles, so the pore structure formed was relatively loose. At $1150^{\circ} \mathrm{C}$, with the increase of forming pressure and holding time, the sand particles were connected by granular and filamentous glass into a larger area, and the pore size of the ceramics decreased. In addition, it can be found that the porous ceramics sintered at $1100^{\circ} \mathrm{C}$ show red color, while with the increase of temperature and the extension of holding time, the color of the ceramic will change from red to black, which is related to the transformation of red ferric oxide $s$ into black ferrosoferric oxide in sand particles. 

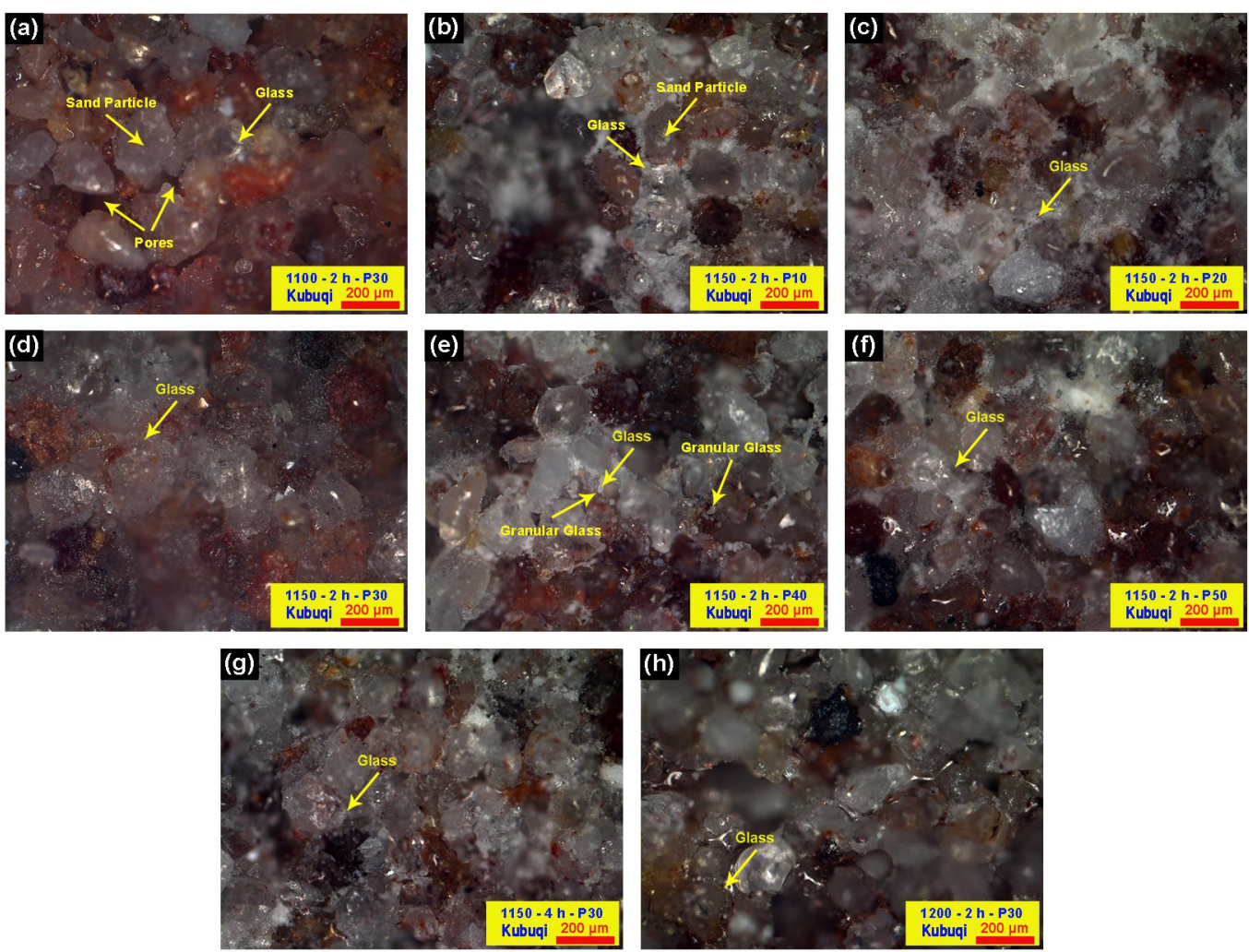

Fig. 5. CLSM images of porous ceramics synthesized from Kubuqi desert sand under various conditions.

\subsection{Sintering properties of porous ceramics}

As can be seen from Fig. 6, the shrinkage rate of ceramics synthesized from Kubuqi desert sand increased with the increase of sintering temperature and holding time. When sintered at $1100^{\circ} \mathrm{C}-1200^{\circ} \mathrm{C}$ for $2 \mathrm{~h}$, the apparent porosity and water absorption decreased, which were consistent with the increase of shrinkage. However, when sintered at $1150^{\circ} \mathrm{C}$ for $2 \mathrm{~h}-4 \mathrm{~h}$, the apparent porosity and water absorption of the ceramics increased. Combined with phase content (Fig. 2) and SEM images (Fig. 3b-Fig. 3c), the feldspar phase transforms into quartz and glass phases with an increase of holding time. Among them, the glass phase increases the contact area between particles, and small pores are easy to be filled up, while those pores close to the large pores are annexed into the larger pores $[18,19]$. In general, the number of pores is less, but the volume of open pores becomes larger. For the bulk density of ceramics, it agrees well with the shrinkage rate of ceramics (Fig. 6b). 

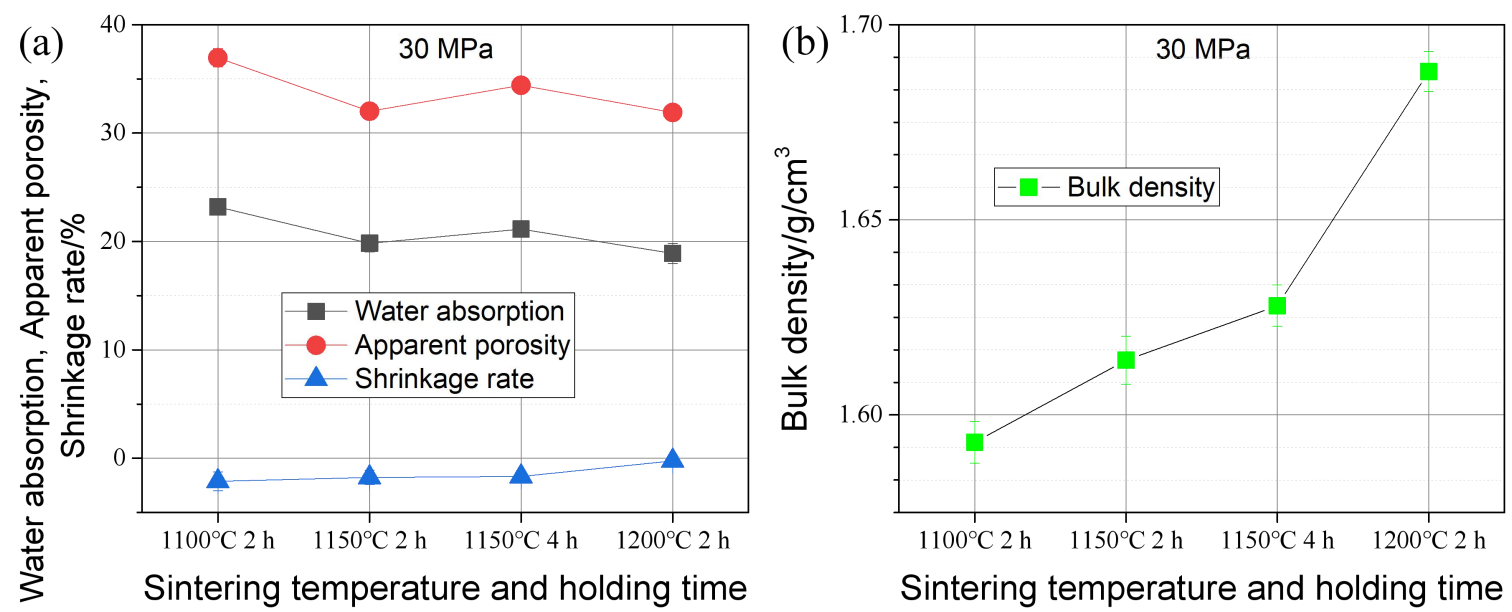

Fig. 6. Sintering properties of porous ceramics synthesized under $30 \mathrm{MPa}$ forming pressure, (a) water absorption, apparent porosity and shrinking percentage, (b) bulk density.

The ceramics synthesized from the Kubuqi desert sand with smaller particle size have higher bulk density and shrinkage, and lower apparent porosity and water absorption (Fig. 7a-Fig. 7d). In addition, with the increase of forming pressure, the bulk density of the porous ceramics increased, and the water absorption, apparent porosity and shrinkage decreased, indicating that high forming pressure is not conducive to the synthesis of porous ceramics with high porosity. The water permeability of porous ceramics sintered at $1150^{\circ} \mathrm{C}(30 \mathrm{MPa})$ increased with the extension of holding time from $2 \mathrm{~h}$ to $4 \mathrm{~h}$. In addition, under the same conditions, when formed under $50 \mathrm{MPa}$ or sintered at $1200^{\circ} \mathrm{C}$, the permeability of ceramics increased (Fig. 7e).
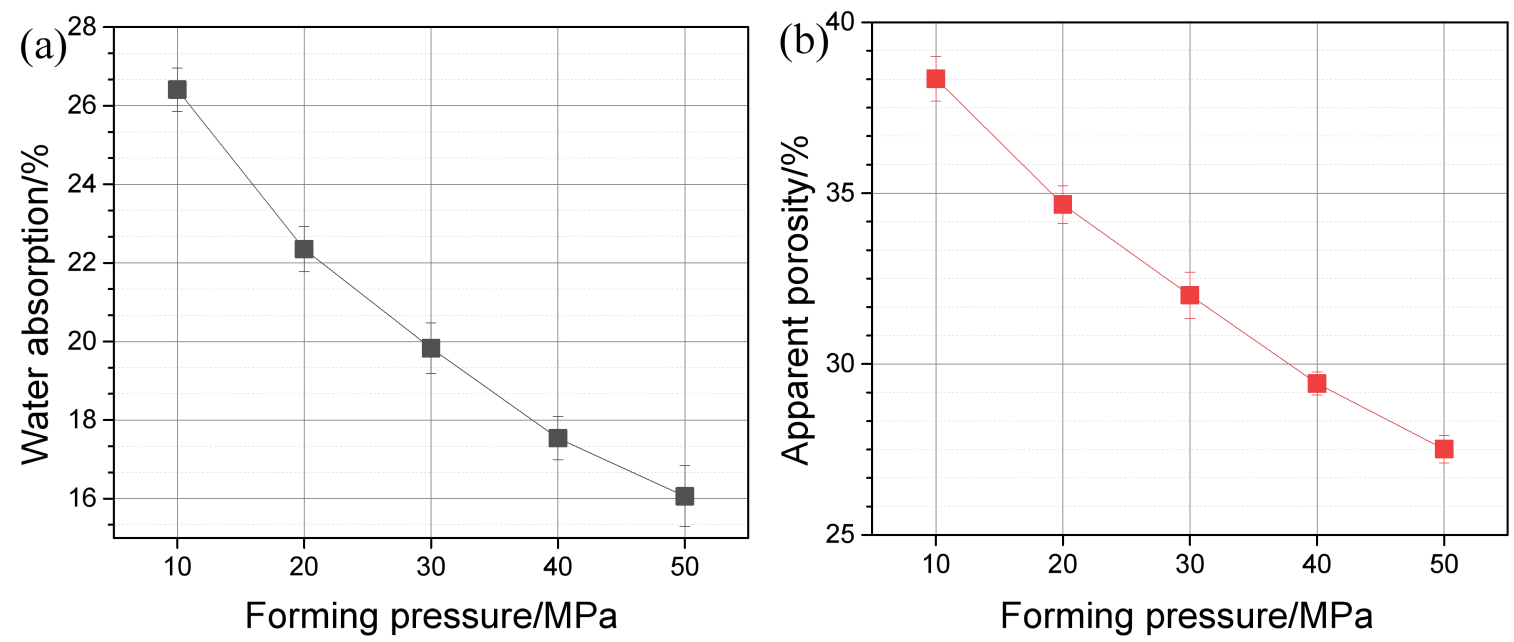

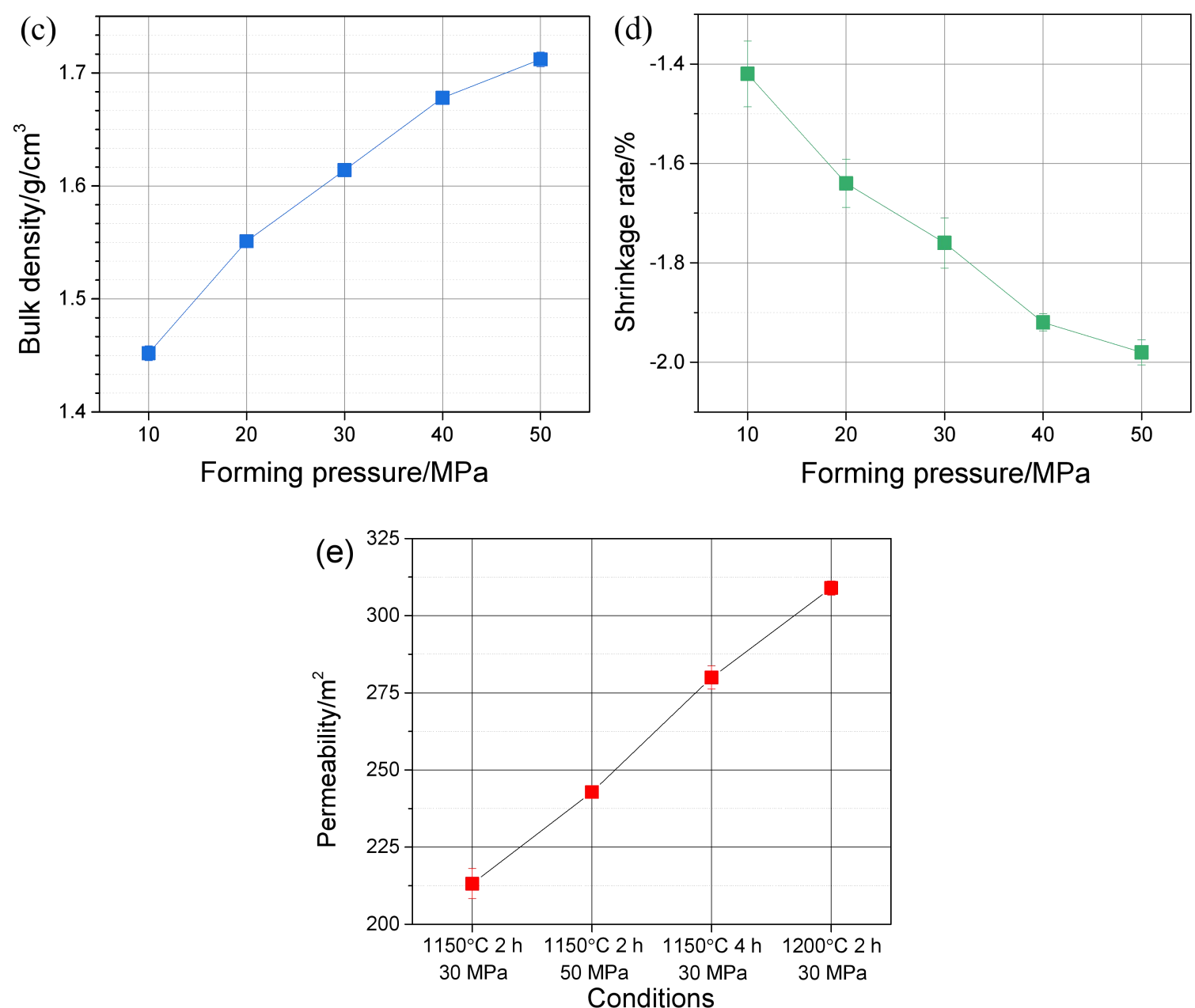

Fig. 7. Sintering properties of porous ceramics sintered at $1150^{\circ} \mathrm{C}$ for $2 \mathrm{~h}$, (a) water absorption, (b) apparent porosity, (c) bulk density, (d) shrinking rate and (e) permeability.

\subsection{Mechanical properties of porous ceramics}

With the increase of sintering temperature, both the bending strength and compressive strength of the porous ceramics showed an increasing trend, and both reach the maximum when sintered at $1150^{\circ} \mathrm{C}$ for $4 \mathrm{~h}$ (Fig. 8a). In addition, the phase content (Fig. 2) showed that when sintered at $1150^{\circ} \mathrm{C}$ for a longer time, the feldspar phase was transformed into the liquid phase, and the increase of the connecting area of porous ceramic particles improved the mechanical properties. The mechanical properties of the porous ceramics were improved with the increase of forming pressure, indicating that the forming pressure was beneficial to increase the contact area between desert sand particles and form a large area of glass connection, thus improving the mechanical properties of the ceramics (Fig. 8b) [20]. In 
addition, bending strength is related to the grain size of sand particles acting as the skeleton support in the ceramic. The ceramic with a large grain size is not easy to compress, while the ceramic with a small grain size is of higher density, leading to a higher bending strength [21].
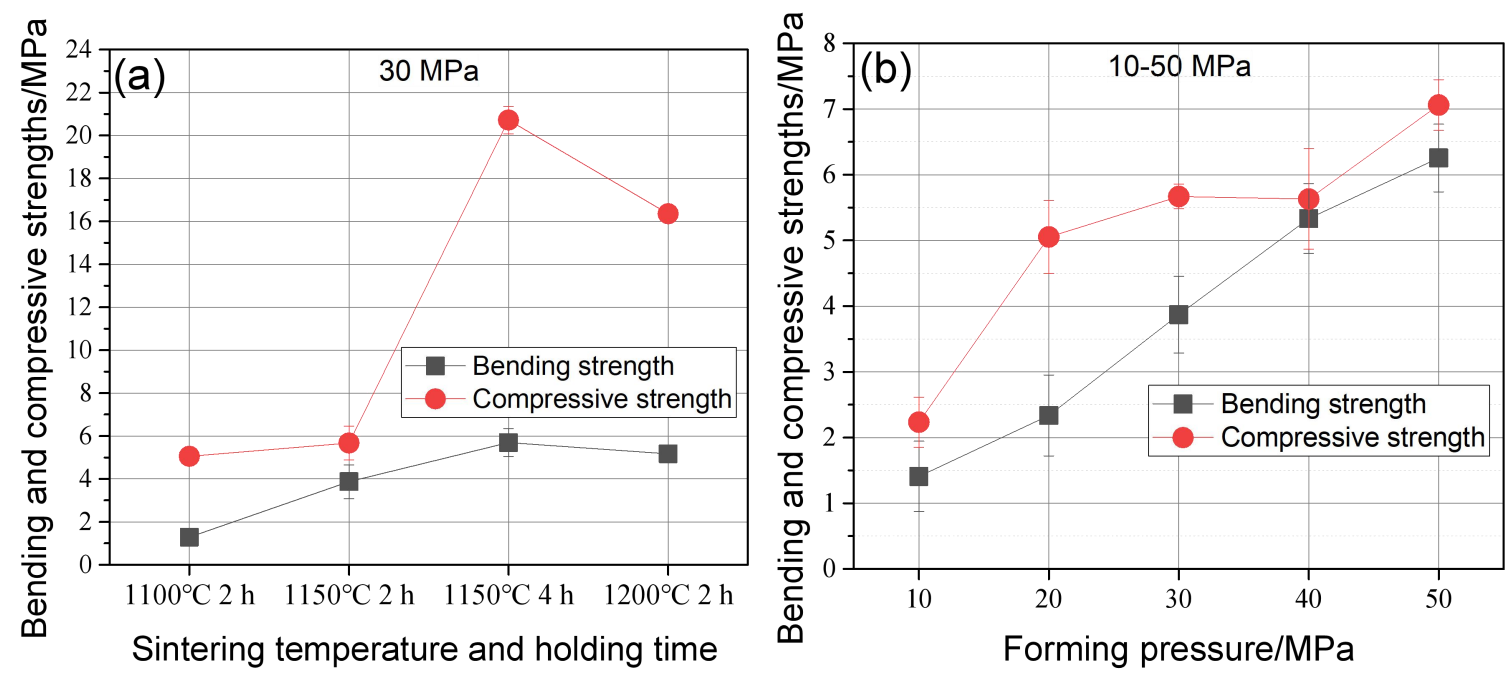

Fig. 8. Bending strength and compressive strength of porous ceramics (a) $30 \mathrm{MPa}$ forming pressure,

(b) $1150^{\circ} \mathrm{C}$ for $2 \mathrm{~h}$.

\subsection{Thermal conductivity of porous ceramics}

As can be seen from Fig. 9, when formed under $30 \mathrm{MPa}$ and sintered for $6 \mathrm{~h}$, the thermal conductivity of porous ceramics increased with an increase of sintering temperature. When sintered at $1150^{\circ} \mathrm{C}$ for $6 \mathrm{~h}$, the thermal conductivity of the ceramic increased with the increase of forming pressure. When formed under $30 \mathrm{MPa}$ and sintered at $1200^{\circ} \mathrm{C}$, the thermal conductivity of the porous ceramics reached to a maximum. The above data indicate that the higher the forming pressure or sintering temperature, the denser the porous ceramics, and the significant ratio of solid heat transfer ultimately leads to high thermal conductivity and poor heat insulation effect. 


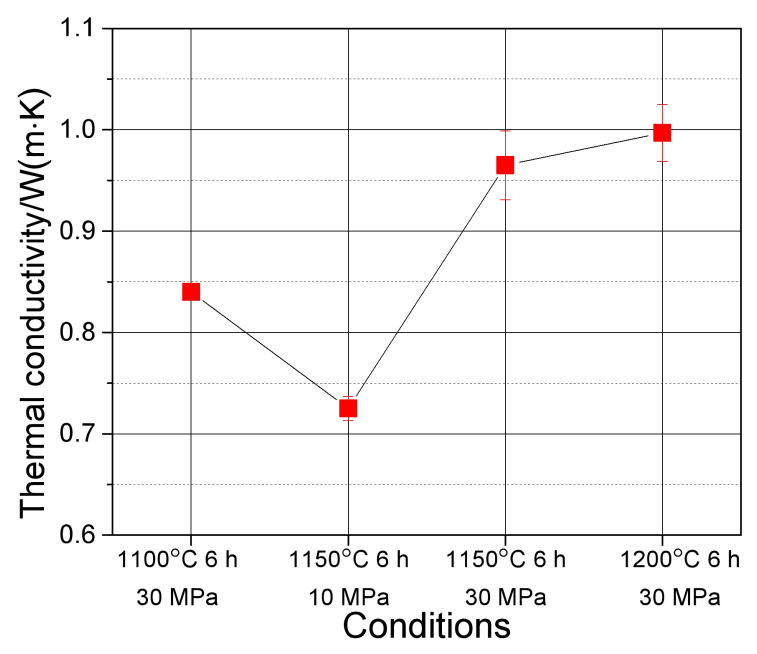

Fig. 9. Thermal conductivity of porous ceramics synthesized under different conditions.

The internal structure of porous ceramics synthesized from desert sand is composed of quartz particles and their solid-phase connection, open pores for air passage and closed pores, and its thermal conduction mechanism is more complex than that of single phase dense materials. Based on the three main modes of heat conduction (heat conduction, heat convection and heat radiation), the heat transfer process of porous ceramics from high temperature part to low temperature part mainly has two transfer paths: conduction in solid-phase and heat transfer in pore. In the solid-phase transfer, the heat transfer rate and direction will change when the heat touches the pore. Because the thermal conductivity rate of the gas phase is slower than that of the solid-phase, the movement of the gas molecules in the small pores or closed pores is limited and the thermal conductivity is reduced, while the interconnected open pores can make the heat flow through directly, and the reduction of the thermal conductivity of the ceramic is not as large as the closed pores [22,23]. Finally, porous ceramics with a low solid-phase ratio and a high proportion of closed pores have lower thermal conductivity. According to the microstructure of ceramics, the change of thermal conductivity is basically inversely proportional to the apparent porosity of ceramics, in line with the theory that the higher the porosity of insulation materials, the lower the thermal conductivity [24].

\subsection{Formation mechanism of porous ceramics for desert sand}

From the backscattered electron images of the cross section of desert sand particles in Kubuqi 
(Fig. 10), it can be seen that there are phase distributions of different shapes and colors in the desert sand particles. It can be seen from the energy spectrum (Table 2) that the unsintered desert sand is mainly composed of feldspar phase. When sintered at $500^{\circ} \mathrm{C}$ for $2 \mathrm{~h}$, the desert sand is mainly composed of a large amount of quartz and a small amount of feldspar phase, indicating that the feldspar phase is gradually decomposed into quartz and glass phase after high temperature. When sintered at $1000^{\circ} \mathrm{C}$, desert sand particles are mainly composed of quartz phase, while other phases gradually disappear and transform into the glass phase, which agrees with the XRD results of desert sand (Fig.1-Fig. 2).
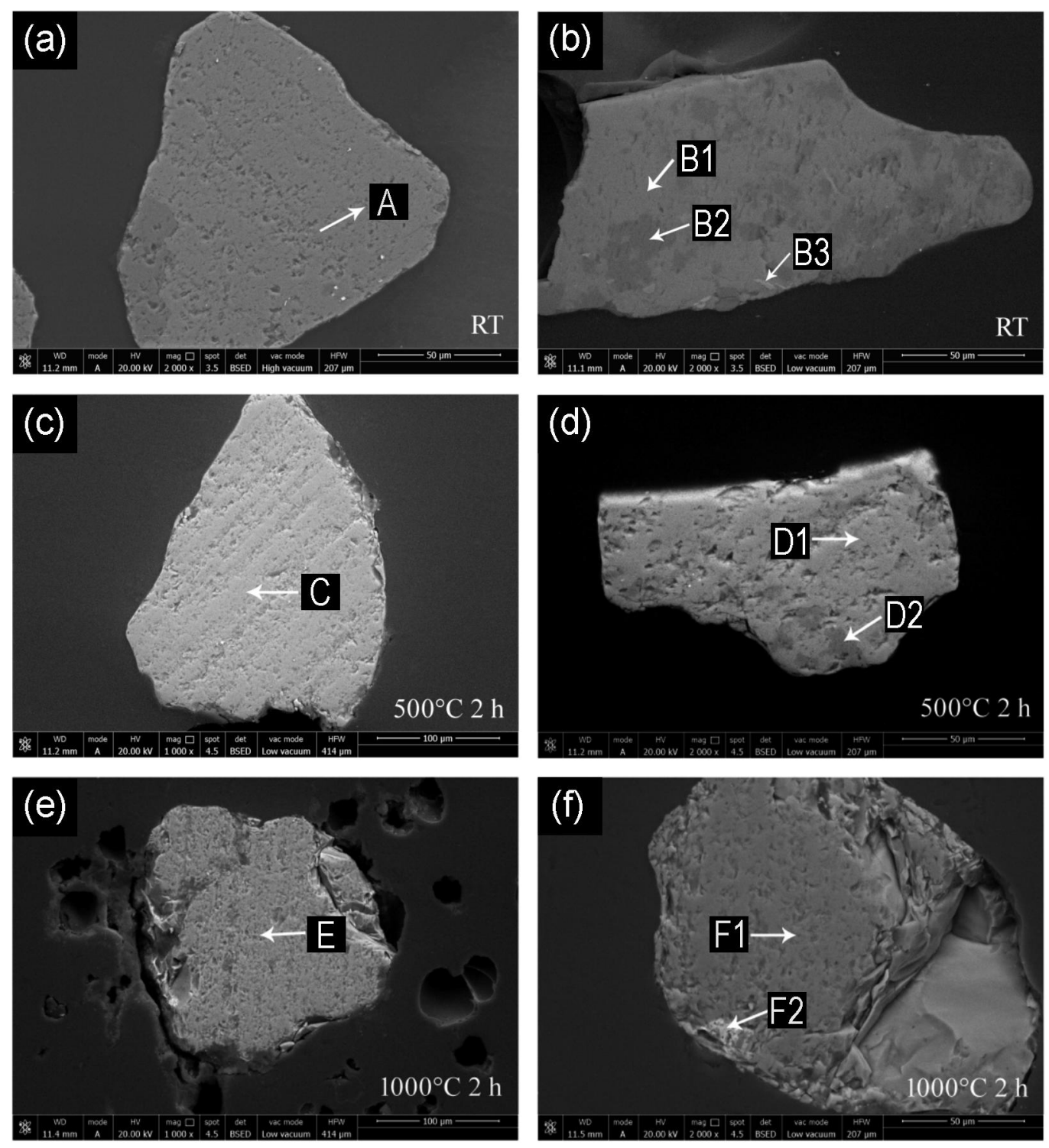

Fig. 10. Backscattered electron images of the sand particle sections from Kubuqi desert sintered at 
different temperatures: (a, b) unsintered; (c, d) $500^{\circ} \mathrm{C}$ for $2 \mathrm{~h} ;(\mathrm{e}, \mathrm{f}) 1000^{\circ} \mathrm{C}$ for $2 \mathrm{~h}$.

Table 2. Results of energy spectrum analysis at various points of desert sand particles in Figure 10 $/ \mathrm{wt} \%$.

\begin{tabular}{ccccccccc}
\hline Element & $\mathrm{O}$ & $\mathrm{Na}$ & $\mathrm{Al}$ & $\mathrm{Si}$ & $\mathrm{K}$ & $\mathrm{Ca}$ & $\mathrm{Ti}$ & Phase \\
\hline PointA & 62.54 & - & 6.64 & 21.66 & 9.16 & - & - & Orthoclase \\
PointB1 & 51.09 & 0.39 & 8.74 & 28.48 & 11.30 & - & - & Orthoclase \\
PointB2 & 52.35 & 6.85 & 9.15 & 29.39 & 1.26 & 1.00 & - & Albite \\
PointC & 54.89 & - & - & 45.11 & - & - & - & Quartz \\
PointD1 & 47.34 & 0.78 & 9.14 & 31.26 & 11.48 & - & - & Orthoclase \\
PointD2 & 52.03 & 1.51 & 8.55 & 28.02 & 9.89 & - & - & Sodium-rich Orthoclase \\
PointE & 55.04 & - & - & 44.96 & - & - & - & Quartz \\
PointF1 & 54.26 & - & - & 45.74 & - & - & - & Quartz \\
\hline
\end{tabular}

The formation mechanism of porous structure for desert sand can be briefly described in three steps (Fig. 11). The first step, unsintered desert sand particles are contacted by the pressure forming, but no connection is formed. The second step, after high temperature sintering, the feldspar phase in the desert sand particles transforms into liquid phase and precipitates on the surface of the particles to form a glass connection layer, and then the glass connection layer connects with each other. With the changes of temperature and holding time, the volume of liquid phase formed is different, affecting the size of the pores. In addition, the transformation of iron oxide into ferroferric oxide releases oxygen. When glass viscosity is larger $\left(1100^{\circ} \mathrm{C}\right)$, the gas will be closed in the glass to form spherical bubbles, that is, closed pores. When the temperature increases further, the glass viscosity and surface tension decrease, and the bubble movement resistance in the melt decreases, resulting in bubble expansion and bubble annexation phenomenon $\left(1150^{\circ} \mathrm{C}-1200^{\circ} \mathrm{C}\right)$. The third step, the glass is cooled and combined with sand particles to form a stable porous structure. 


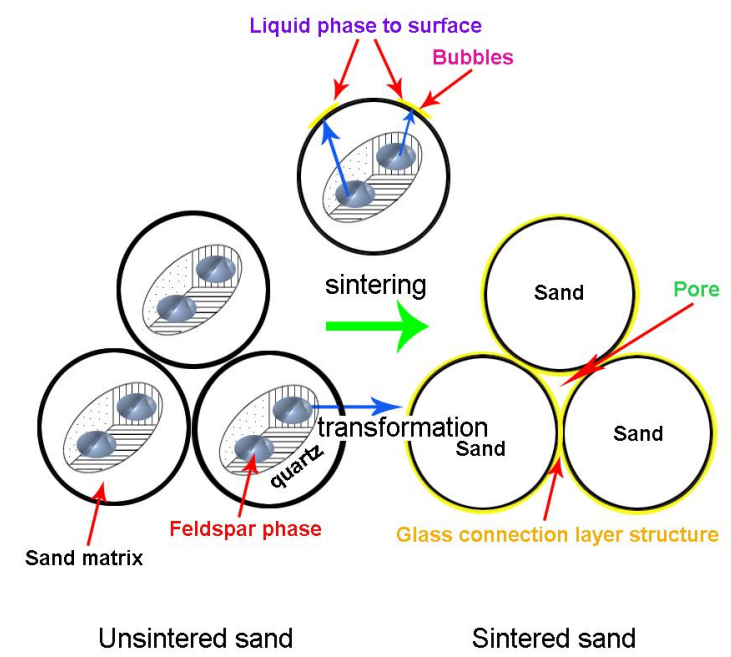

Fig. 11. Formation mechanism of porous structure for desert sand.

\section{Conclusions}

Porous ceramic materials with uniform pores were successfully synthesized by particle stacking from the Kubuqi $\mathrm{r}$ desert sand. The formation of more glass phase at $30 \mathrm{MPa}$ is helpful to the formation of porous ceramic. Under $30 \mathrm{MPa}$ forming pressure, 80-100 mesh Kubuqi desert sand produced $15.2 \mathrm{wt} \%$ of glass phase when sintered at $1200^{\circ} \mathrm{C}$ for $2 \mathrm{~h}$.

Increasing sintering temperature and holding time promoted the transformation of pore morphology from open pore to closed one, and the high temperature decomposition of ferric oxide in the desert sand also resulted in the formation of a small number of spherical closed pores. In addition, increasing the forming pressure is beneficial to reduce the pore size of ceramics.

Under $30 \mathrm{MPa}$, the ceramic samples sintered at $1100^{\circ} \mathrm{C}$ for $2 \mathrm{~h}$ had the highest apparent porosity of $36.94 \%$, the highest water absorption of $23.19 \%$, the lowest linear shrinkage of $-2.12 \%$ and the lowest bulk density $1.59 \mathrm{~g} / \mathrm{cm}^{3}$. In addition, the apparent porosity, water absorption, linear shrinkage and bulk density of the ceramics decreased with the increase of forming pressure. Under $30 \mathrm{MPa}$, the highest permeabilities of ceramic samples sintered at $1200^{\circ} \mathrm{C}$ for $2 \mathrm{~h}$ was $308.96 \mathrm{~m}^{2}$. The mechanical properties of the porous ceramics were 
improved with the increase of forming pressure. Under $30 \mathrm{MPa}$, the ceramic samples sintered at $1150^{\circ} \mathrm{C}$ for $4 \mathrm{~h}$ had the best bending strength of $5.69 \mathrm{MPa}$ and compressive strength of 20.72 MPa. As the forming pressure and sintering temperature increase, the porous ceramics become compact and the proportion of solid heat transfer increased, leading to the increase of thermal conductivity of ceramics. Finally, when formed at $10 \mathrm{MPa}$ and sintered at $1150^{\circ} \mathrm{C}$ for $6 \mathrm{~h}$, the ceramic sample had the lowest thermal conductivity of $0.73 \mathrm{~W}(\mathrm{~m} \cdot \mathrm{K})$. When formed at $30 \mathrm{MPa}$ and sintered at $1100^{\circ} \mathrm{C}$ for $6 \mathrm{~h}$, the the ceramic sample had a low thermal conductivity of $0.84 \mathrm{~W}(\mathrm{~m} \cdot \mathrm{K})$.

\section{Acknowledgments}

This work was supported by the National College Student Innovation and Entrepreneurship Training Program, China (202010128005) and Scientific research project of Inner Mongolia University of Technology, China (ZY201918).

\section{References}

[1] Y.L. Yang, F.L. Liu, Q.B. Chang, Z.W. Hu, Q.K. Wang and Y.Q. Wang, Ceram., 2, 286-295 (2019).

[2] Y.P. Dong, X.M. Fan, H.J. Wei, Z.X. Hou, M.H. Li, Q. Qu, X.W. Yin, L.F. Cheng and L.T. Zhang, Ceram. Int., 46, 22474-22481 (2020).

[3] Z.R. Fan, S.Y. Zhou, A.L. Xue, M.S. Li, Y. Zhang, Y.J. Zhao and W.H. Xing, Chinese J. Chem. Eng., 29, 417-425 (2021).

[4] Y.L. Feng, S.J. Wang, B. Feng, R. Wang, Y. He and T. Zhang, Sensor. Actuat. A-Physical, 152, 104-109 (2009).

[5] T. Moritz and H.J. Richter, J. Eur. Ceram. Soc., 27, 4595-4601 (2007).

[6] N.A. Shvetsova, I.A. Shvetsov, M.A. Lugovaya and E.I. Petrova, J. Adv. Dielectr., 11, 2160006 (2021). 
[7] M. Fuji, Y. Shiroki, R.L. Menchavez, H. Takegami, M.Takahashi, H. Suzuki, S. Izuhara and T. Yokoyama, Powder Technol., 172, 57-62 (2007).

[8] L. Guan, B.B. Fan, C. Liu, H.L. Wang, L. Xing, D.L.Chen and R. Zhang, Ceram. Int., 35, 1905-1908 (2009).

[9] Z.H. Tang, J. Wei, L. Yung, B.W. Ji, H.Y. Ma, C.Q. Qiu, K. Yoon, F. Wan, D.F. Fang, B.S. Hsiao and B. Chu, J. Membrane Sci., 328, 1-5 (2009).

[10] S.C. Yao, L.F. Zhang, Y.M. Zhu, J. Wu, Z.M. Lu and J.D. Lu, Waste Manage., 102, 492-498 (2020).

[11] S.U. Qadir, V. Raja, W.A. Siddiqi, M.N. Alyemeni, L. Wijaya and P. Ahmad, Arab. J. Geosc., 14, 116 (2021).

[12] B. Nzuki, C. Niyonzima, L.Q. Luo, P.F. Zhou and X. Tu, China. J. Miner. Mater. Char. Eng., 7, 81-102 (2019).

[13] A. Mocciaro, M.B. Lombardi and A.N. Scian, Refract. Ind. Ceram., 58, 65-68 (2017).

[14] X.Z. Zhang, R.J. Wang, G.W. Liu, H.C. Shao, K. Zhang, Z.Q. Shi and G.J. Qiao, Mater. Sci. Forum, 814, 574-578 (2015).

[15] X.S. Zhang, L.Y. Xue, F. Yang, Z.H. Shao, H. Zhang, Z.G. Zhao, and K.X. Wang, J. Alloy. Compd., 863, 158763 (2021).

[16] L. Yuan, E.D. Jin, C.Y. Li, Z.L. Liu, C. Tian, B.Y. Ma and J.K. Yu, Ceram. Int., 47, 9017-9023 (2021).

[17] H.L Zhu, S.O. Chen, D. Li. and W.Q. Shao, Phys. Test. Chem. Analysis (Part: A Phys. test.), 42, 289-291 (2006).

[18] V.I. Uvarov, R.D. Kapustin, A.S. Fedotov and A.O. Lirillov, Glass Ceram., 77, 221-225 (2020).

[19] Y.B. Zong, Q.L. Wan and D.Q. Cang, Ceram. Int., 45, 22445-22451 (2019).

[20] S.Z. Salleh, A.A. Kechik, A.H. Yusoff, M.A.A.Taib, M.M. Nor, M. Mohamad, T.G. Tan, A. Ali, M.N. Masri, J.J. Mohamed, S.K. Zakaria, J.G. Boon, F.Budiman and P.T. Teo, J. Clean. Prod., 306, 127264(2021).

[21] D.A. Ivanov, A.I. Sitnikov, G.E. Val'yano, T.I. Borodina and S.D. Shlyapin, Ind. Ceram., 
59, 459-465 (2019).

[22] Q.T. Wang, H.Q. Yu, T. Ben, Q. Li, F.Z. Li, H.J. Xu, H.B. Qiao and Q.Y. Du, J. Aust. Ceram. Soc., 56, 91-98 (2019).

[23] Y. Zhang, Y.J. Wu, X.K.Yang, D.H. Li, X.Y. Zhang, X. Dong, X.H. Yao, J.C. Liu and A.R. Guo, J. Eur. Ceram. Soc., 40, 2090-2096 (2020).

[24] J. Bourret, N. Tessier-Doyen, B. Naït-Ali, F. Pennec, A. Alzina, C.S. Peyratout and D.S. Smith, J. Eur. Ceram. Soc., 33, 1487-1495 (2013). 